\title{
ANALISIS MEDIASI GREEN TRUST PADA PURCHASE INTENTION PRODUK GREEN
}

\author{
Dea Yulyana Suprapto ${ }^{1}$ \\ Efendi $^{2}$ \\ 1,2 Fakultas Ekonomi dan Bisnis, Universitas Katolik Indonesia Atma Jaya, \\ Jakarta, Indonesia
}

\begin{abstract}
In today's era, consumer's attitude in choosing and using the product start to change. Consumers begin to have awareness and concern about the impact of consumption on the environment. Many consumers are now choosing green products because of better value and functionality for consumers and the environment. This study aims to analyze the effect of green perceived value and green perceived risk on green purchase intention with green trust as mediation. Data was obtained by distributing questionnaires to consumers who visit Electronics City Pondok Indah Mall. Sampling technique applied in this research is systematic random sampling. Data was analyzed using SEM (Structural Equation Modeling).
\end{abstract}

Keywords: green perceived value, green perceived risk, green trust, green purchase intention.

\section{PENDAHULUAN}

Global warming atau disebut juga pemanasan global merupakan masalah yang berdampak buruk pada kehidupan dunia dan berdampak negatif bagi kehidupan masyarakat sehingga sekarang ini banyak yang menerapkan beberapa produk dengan kegiatan ramah lingkungan seperti Healthy Food \& Beverage, Electronics Product, dan kosmetik. Mengapa banyak perusahaan yang menciptakan suatu produknya dengan konsep green? Dapat dikatakan, konsep green diciptakan untuk mengurangi dampak lingkungan dengan itu beberapa perusahaan saling berlomba-lomba menerapkan konsep green dengan memanfaatkan sumber energy dan sumber daya alam secara optimal guna untuk membantu mengurangi pemanasan global di dunia.

Saat ini yang kita dapat melihat banyak perusahaan yang menerapkan produk dengan penanganan masalah lingkungan hidup melalui efisiensi 
pengunaan sumber daya yang dapat dilakukan dengan menerapkan 3R (reduce, reuse, dan recycle) yang merupakan inti dari go green, sedangkan untuk emisi rendah karbon dapat menerapkan CO2 Emission Reduction. Melalui konsep green marketing perusahaan dapat memanfaatkan green opportunities, meningkatkan citra perusahaan, menaikkan nilai produk, meningkatkan keunggulan daya saing (Chen, 2008).

Perusahaan elektronik mulai menawarkan berbagai produk ramah lingkungan tanpa penggunaan HCFC (Hydrochlorofluorcarbon). Penggunaan HCFC pada suatu produk dapat meninmbulkan masalah yang serius, dikarenakan kandungan molekul yang tercipta dapat merusak lapisan ozon 1000 kali lipat yang menyebabkan pemanasan global atau yang sering kita dengar dengan efek rumah kaca. Salah satu perusahaan besar produsen alat-alat elektronik yang memproduksi green product adalah LG Electronics Indonesia. LG Electronics telah menetapkan strategi untuk mengembangkan produk yang mengurangi dampak lingkungan sepanjang siklus hidup produk tersebut atau green product. Hal ini diklasifikasikan menjadi tiga kategori yaitu manusia, energy, dan sumber daya. LG Electronics memiliki tiga kategori Air Conditioner (AC) yaitu Inverter Series, Low-watt Series, dan Standard Series. Pada Air Conditioner (AC) Inverter Series memiliki keunggulan yang lebih besar dibandingkan series lainnya. Beberapa kategori keunggulan Inverter Series yaitu membantu pembasmian kuman dan memberikan performa dengan meminimalkan konsumsi listrik hingga $60 \%$.

Perceived Value didefinisikan sebagai nilai yang dirasakan konsumen dan penilaian keseluruhan akan suatu produk dengan apa yang telah dirasakan konsumen (Bolton \& Drew, 1991). Konsumen juga perlu menghindari resiko dari pemakaian suatu produk. Perusahaan harus dengan jelas memaparkan apa isi kandungan dari suatu produk tersebut baik dari komposisi dan apa yang terkandung dalam produk sehingga konsumen dapat mempercayai produk yang akan digunakan. Dalam suatu jurnal ilmiah, perceived risk dapat mempengaruhi kepercayaan konsumen secara negatif (Koehn, 2003).

Kepercayaan adalah sesuatu yang timbul atas suatu perilaku yang telah dilakukan (Hart \& Saunders, 1997). Kepercayaan pelanggan adalah penentu dari jangka pemakaian produk, jika produk dapat dipercaya maka pembelian konsumen akan dilakukan secara terus-menerus (Lee, Park \& Han, 2011). Pada saat konsumen percaya kepada produk maka konsumen akan menaruh kepercayaan yang kuat untuk membeli porduk tersebut dan mempengaruhi niat belinya kepada green product. Kepercayaan konsumen dapat berpengaruh kepada green perceived value dan green perceived risk yang di timbulkan saat pemakaian suatu produk dimana keduanya dapat mempengaruhi green purchase 
intention. Apakah konsumen dapat memperoleh nilai setelah melakukan pemakaian produk dan bagaimana tingkat resiko yang dialami konsumen atas pemakaian produk?

Melihat minat konsumen untuk pembelian green product berbeda-beda di setiap negara, maka akan dilakukan penelitian tentang nilai yang diterima dan resiko yang dirasakan dalam konteks green terhadap niat beli konsumen hijau. Maka, penulis tertarik untuk mengetahui pengaruh Green Perceived Value dan Green Perceived Risk terhadap Green Purchase Intention dengan Green Trust sebagai mediasi pada calon konsumen Air Conditioner Inverter Series LG Electronics.

\section{TELAAH PUSTAKA}

\section{Green Marketing}

Green marketing adalah suatu pemasaran hijau yang telah didefinisikan sebagai semua kegiatan yang dirancang untuk menghasilkan dan membantu meminimalkan dampak lingkungan dengan memenuhi kebutuhan atau keinginan manusia sedemikian rupa sehingga kepuasan akan kebutuhan dan keinginan ini terjadi (Cherian and Jacob, 2012).

Pemasaran hijau juga mengacu pada suatu pergerakan yang berupaya mempromosikan, menetapkan harga, dan mendistribusikan produk dengan melihat kekhawatiran lingkungan (Sarkar, 2012). American Marketing Association (AMA) menyatakan bahwa pendekatan pemasaran hijau adalah pemasaran produk yang terutama berfokus pada keselamatan lingkungan, Ini menggabungkan kegiatan bisnis yang terdiri dari modifikasi kemasan, proses produksi, dan iklan hijau (Yazdanifard \& Mercy, 2011). Sejalan dengan berbagai pendapat di atas. Strategi pemasaran hijau, yang menunjukkan seperangkat strategi pemasaran yang memungkinkan perusahaan untuk melakukannya melayani target pasar dan mencapai tujuan perusahaan tanpa merugikan lingkungan (Al-Salaymeh, 2013). Pada saat bersamaan, ia memfasilitasi penjualan produk dan memiliki keterlibatan dalam perlindungan lingkungan dengan memotivasi keluarga dan teman untuk membeli hijau produk, sehingga melanjutkan pembangunan berkelanjutan di dunia. (Gopalakrishnan, 2013).

\section{Green Product}

Green Product adalah barang atau jasa yang diciptakan untuk meminimalkan dampak lingkungan (Albino, Balice, \& Dangelico, 2009). Istilah "green product" secara luas digunakan untuk menggambarkan produk yang 
mengintegrasikan persyaratan lingkungan dengan menciptakan produk yang bebas limbah dan menciptakan produk untuk mengurangi permasalahan kesehatan di dalamnya (Baumann, Boons, \& Bragd, 2002).

\section{Green Perceived Value}

Perceived value didefinisikan oleh Chen dan Chang (2012) sebagai penilaian keseluruhan konsumen atas keuntungan bersih suatu produk atau layanan yang diterima dan apa yang diberikan berdasarkan keinginan lingkungan konsumen, harapan yang berkelanjutan, dan kebutuhan hijau.

Nilai yang dirasakan bukan hanya komponen penting bagi hubbungan jangka panjang pelanggan, tapi juga memainkan peran penting dalam mempengaruhi niat membeli (Zhuang, Cumiskey, Xiao, \& Alford, 2010) dan kepercayaan pelanggan (Kim, Zhao, \& Yang, 2008). Nilai yang dirasakan konsumen juga dapat dirasakan oleh konsumen, jadi jika nilai yang tinggi dan resiko rendah, maka akan meningkatkan kepercayaan konsumen terhadap pembelian suatu produk (Kwok, 2015). Persepsi adalah penilaian keseluruhan dari suatu produk berdasarkan persepsi apa yang diterima dan diberikan. Green Perceived Value bisa diartikan sebagai keuntungan bersih dari penilaian atas jasa. Semakin besar kepercayaan konsumen dari manfaat yang dirasakan terhadap sebuah produk dan produk, maka semakin besar peluang konsumen tersebut akan melakukan suatu perilaku pembelian pada produk tersebut. Berdasarkan pada kesadaran lingkungan saat ini, mendefinisikan green perceived value sebagai penilaian seorang konsumen secara keseluruhan terhadap keuntungan bersih dari sebuah produk barang atau jasa yang dibandingkan antara apa yang mereka terima dan mereka berikan berdasarkan pada hasrat mereka terhadap lingkungan, ekspektasi yang berkelanjutan dan kebutuhan akan penghijauan.

\section{Green Perceived Risk}

Perceived risk merupakan sebuah konsekuensi yang mungkin terjadi saat melakukan pengambilan keputusan (Peter \& Ryan, 1976). Karena perceived risk adalah sebuah kombinasi antara konsekuensi negatif dan ketidakpastian, penilaian dari perceived risk dapat mempengaruhi keputusan pembelian konsumen (Aaker, 1996). Pengurangan dari risiko yang didapat mengacu pada peningkatan kemungkinan adanya pembelian dan pada kenaikan minat beli konsumen, oleh karena itu perceived risk berhubungan negatif dengan minat beli (Wood, Scheer, Corfman, \& Lynch, 1996). Dalam teori perceived risk berargumen bahwa konsumen tertarik untuk meminimalisasi perceived risk mereka dibandingkan dengan memaksimalisasi utilitas mereka (Mitchell, 1999). 
Konsumen mengambil sebuah keputusan saat melakukan pembelian suatu produk, saat itulah konsumen merasa mengorbankan resiko apakah produk yang dibeli sesuai dengan harapan ataupun sebaliknya. Perceived risk memiliki dua dimensi yaitu ketidakpastian dan konsekuensi. Tingkat risiko yang diterima konsumen terhadap risiko yang diterimanya merupakan faktor yang mempengaruhi strategi pembelian (Schiffman \& Kanuk, 2011).

\section{Green Purchase Intention}

Menurut Kotler \& Keller (2012, p.166), terdapat pengertian konsumen melakukan proses keputusan pembelian. Ada beberapa pertanyaan yang mendasarinya who, what, when, where, how and why.

Green consumer didefinisikan secara umum sebagai orang yang mengadopsi perilaku ramah lingkungan. Green consumer lebih terkontrol secara internal karena mereka percaya bahwa konsumen secara individu bisa efektif dalam melakukan perlindungan terhadap lingkungan. Dengan demikian, mereka merasa menjaga lingkungan tidak semata-mata hanya pekerjaan pemerintah saja tetapi harus mulai dari suatu individu yang sadar bahwa menjaga lingkungan adalah tugas bersama dan tidak dapat dilimpahkan oleh pemerintah saja. Keterbukaan pikiran mereka membantu mereka untuk menerima produk hijau dan juga perilaku hijau dengan mudah (Shamsadani, 1993).

Terkait dengan topik penelitian ini, penulis merujuk salah satu jurnal acuan dari (Chen \& Chang, 2012). Penelitian ini menggunakan pendekatan kuantitatif, dan survey disebarkan melalui email secara random kepada pelanggan yang sudah pernah melakukan pembelian produk informasi dan elektronik di Taiwan sebanyak 800 kuisioner dan mendapati 258 diantaranya valid dan dapat digunakan. Dalam penelitian tersebut, ditemukan bahwa green perceived value memiliki pengaruh signifikan yang positif terhadap green trust, dan green perceived risk tidak memiliki pengaruh negatif yang signifikan terhadap green trust. Dan berdasarkan hasil tersebut mendukung adanya argumen dan juga gambaran bahwa green trust berpengaruh secara signifikan terhadap green purchase intentions.

Penelitian sejenis juga dilakukan oleh (Chen, 2010). Penelitian ini dilakukan di Taiwan dengan konsumen pengguna produk informasi dan elektronik sebagai respondennya. Kuisioner sebanyak 650 disebarkan secara random melalui email dan didapati 254 data valid yang dapat digunakan. Hasil dari penelitian ini menunjukkan green brand image memiliki pengaruh signifikan terhadap green trust. 
Dari kedua penelitian tersebut, penulis ingin meneliti tentang pengaruh Green perceived value dan green perceived risk terhadap green purchase intention dengan green trust sebagai mediasi yang mengadopsi model penelitian dari (Chen \& Chang, 2012). Dengan pengambilan data menggunakan random sampling approach dan pengolahan data menggunakan SPSS diharapkan dapat mengembangkan lebih jauh lagi penelitian yang penulis jadikan acuan.

\section{METODE PENELITIAN}

Metode pengumpulan data menggunakan kuisioner sebagai instrument penelitian, yang terdiri dari 18 indikator yang terbaki menjadi lima bagian. Jenis data yang digunakan pada penelitian penulis adalah data primer. Data primer adalah data yang dikumpulkan sendiri oleh perorangan/suatu organisasi langsung melalui objeknya (Supranto, 2016, p.335). Metode pengumpulan sampel menggunakan systematic random sampling. Systematic random sampling dapat dilakukan dengan pengambilan sampel dari populasi yang sangat besar. Pengambilan sampel melibatkan populasi dalam sistematika tertentu. Pengambilan sampel secara sistematis adalah suatu metode dimana hanya unsur pertama dari sampel yg dipilih secara acak sedang unsur-unsur selanjutnya dipilih secara sistematis menurut suatu pola tertentu. Berdasarkan rumus pengambilan sampel secara sistematik diperoleh jumlah sampel sebagai berikut:

$$
\begin{aligned}
& k=\frac{N}{n} \\
& k=\frac{600}{200}=3
\end{aligned}
$$

Keterangan:

$$
\mathrm{N}=\text { Populasi dan } \mathrm{k}=\text { Sampling Interval }
$$

Populasi di dapatkan melalui data supervisor Electronic City sebesar 600 yang merupakan jumlah rata-rata pengunjung per minggu. Setelah mendapatkan jarak interval, maka tahapan berikutnya adalah menentukan nomor berapa peneliti akan mulai menghitung. Penetapan nomor pertama ini dilakukan secara acak atau random, sampel berikutnya ditentukan dengan menambahkan interval dan seterusnya. Dari data yang sudah didapatkan, maka peneliti akan memberikan kuesioner pada konsumen dengan kelipatan 3, 6, 9, 15 dan seterusnya. Data penelitian dikumpulkan dengan menyebarkan 200 kuesioner kepada responden yang tepatnya adalah para konsumen yang sedang berkunjung ke toko Electronics City Pondok Indah Mall pada tanggal 6 Juni - 3 Juli pukul 13.00 WIB 20.00 WIB. Namun, dari 200 responden yang didapatkan, hanya 177 responden 
yang menganggap $A C$ Inverter Series $L G$ Electronics sebagai produk ramah lingkungan.

\section{HASIL DAN PEMBAHASAN}

Subyek dalam penelitian ini adalah konsumen di area Jabodetabek yang mengunjungi toko elektronik dari produk Air Conditioner (AC) Inverter Series LG Electronics.

Uji validitas menurut Ghozali \& Fuad (2008, p.329) adalah kemampuan suatu indikator dalam mengukur variable laten. Berikut nilai standardized loading factor pada indikator variabel yang diteliti:

\section{Tabel 1}

Hasil Uji Validitas (Confirmatory Factor Analysis)

\begin{tabular}{cc}
\hline Kode & Confirmantory Factor Analysis \\
\hline GPV1 & 0.84 \\
GPV2 & 0.82 \\
GPV3 & 0.87 \\
GPV4 & 0.79 \\
GPV5 & 0.62 \\
GPR1 & 0.85 \\
GPR2 & 0.86 \\
GPR3 & 0.88 \\
GPR4 & 0.79 \\
GPR5 & 0.62 \\
GT1 & 0.79 \\
GT2 & 0.90 \\
GT3 & 0.82 \\
GT4 & 0.77 \\
GT5 & 0.64 \\
GPI1 & 0.68 \\
GPI2 & 0.84 \\
GPI3 & 0.87 \\
GPI4 & 0.74 \\
\hline Sumber: data yang diolah (2017)
\end{tabular}

Berdasarkan hasil table diatas, semua indikator dapat dikatakan valid karena validitas suatu indicator dapat dievaluasi dengan tingkat signifikansi pengaruh antara suatu variabel dengan indikatornya. Indikator penelitian dapat dikatakan valid apabila mempunyai nilai Standardized Loading Factor (SLF) di atas 0.50 atau 0.70 . 
Tabel 2

Hasil Uji Reliabilitas

\begin{tabular}{lc}
\hline Variabel & $\begin{array}{c}\text { Composite } \\
\text { Reliability }\end{array}$ \\
\hline Green Perceived Value & 0.89 \\
Green Perceived Risk & 0.90 \\
Green Trust & 0.89 \\
Green Purchase Intention & 0.87 \\
\hline \multicolumn{2}{l}{ Sumber: data yang diolah (2017) }
\end{tabular}

Berdasarkan perhitungan diatas, dapat dikatakan bahwa variabel dalam penelitian ini memiliki reliabilitas yang baik. Hal tersebut dapat dilihat dari nilai composite reliability yang $>0.6$.

Tabel 3

Penilaian Model GoodFit

\begin{tabular}{|c|c|c|c|c|}
\hline $\begin{array}{c}\text { Fit } \\
\text { Measure }\end{array}$ & $\begin{array}{c}\text { Good } \\
\text { Fit }\end{array}$ & $\begin{array}{c}\text { Acceptable } \\
\text { Fit }\end{array}$ & $\begin{array}{c}\text { Hasil } \\
\text { Penelitian }\end{array}$ & $\begin{array}{c}\text { Tingkat } \\
\text { Kecocokan }\end{array}$ \\
\hline$x^{2} / d f$ & $0 \leq x^{2} \leq 2 d f$ & $2.00<x^{2} \leq 3.00$ & 2.540 & Acceptable fit \\
\hline RMSEA & $0 \leq \mathrm{RMSEA} \leq 0,05$ & $0.05 \leq \mathrm{RMSEA} \leq 0.08$ & 0.091 & Marginal fit \\
\hline SRMR & $0 \leq S R M R \leq 0.05$ & $0.05 \leq S R M R \leq 0.10$ & 0.060 & Acceptable fit \\
\hline GFI & $0.80 \leq \mathrm{GFI} \leq 0.90$ & & 0.82 & Good fit \\
\hline $\mathrm{NFI}$ & $0.95 \leq \mathrm{NFI} \leq 1.00$ & $0.90 \leq N F I<0.95$ & 0.93 & Acceptable fit \\
\hline $\mathrm{CFI}$ & $0.97 \leq \mathrm{CFI} \leq 1.00$ & $0.95 \leq \mathrm{CFI}<0.97$ & 0.96 & Acceptable fit \\
\hline $\mathrm{IFI}$ & $\mathrm{IFI} \geq 0.90$ & & 0.96 & Good fit \\
\hline RFI & Mendekati 1 & & 0.92 & Good fit \\
\hline NNFI & $0.97 \leq \mathrm{NNFI} \leq 1.00$ & $0.95 \leq \mathrm{NNFI}<0.97$ & 0.95 & Acceptable fit \\
\hline AGFI & $.90 \leq \mathrm{AGFI} \leq 1.00$ & $0<A G F I<1.00$ & 0.77 & Acceptable fit \\
\hline
\end{tabular}

Sumber: data yang diolah (2017)

Berdasarkan hasil pengujian penilaian model fit (Goodness of Fit) diatas, dapat disimpulkan bahwa model penelitian sudah cukup baik. Hal tersebut ditunjukan dengan hasil pada penilaian model fit dan sejumlah indicator yang umumnya (dominan) menunjukan model dapat diterima, walaupun ada beberapa indikator yang menunjukan bahwa model tersebut tidak baik. 
Persamaan 1:

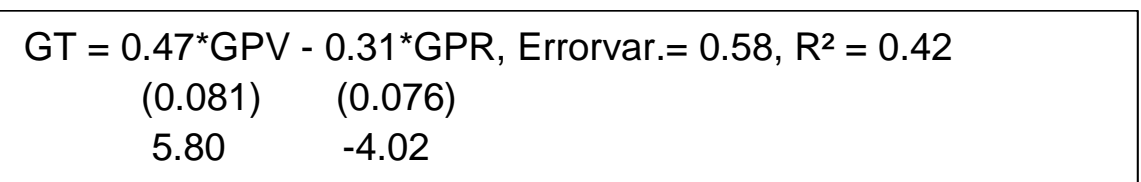

Dari persamaan struktural diatas, dapat dijelaskan terdapat pengaruh langsung signifikan dari Green Perceived Value terhadap Green Trust dengan nilai $\mathrm{t}$ hitung 5,80 (t-value > 1,96). Variabel Green Perceived Value (GPV) dan Green Perceived Risk (GPR) dapat menjelaskan variable Green Trust (GT) sebesar 42\%, sedangkan $58 \%$ dijelaskan oleh faktor lain yang tidak terdapat pada model.

Berdasarkan hal tersebut maka dapat digunakan untuk menjawab rumusan masalah yang pertama, yaitu ada pengaruh yang signifikan antara Green Perceived Value terhadap Green Trust atau dapat dikatakan bahwa $\mathrm{H} 1$ diterima.

Sementara itu untuk variable Green Perceived Risk. Di dalam persamaan 1 dapat diketahui bahwa pengaruh Green Perceived Risk terhadap Green Trust memiliki nilai t-hitung $\|-4,02\|$ (t-value $>1,96$ ). Hal ini menunjukan adanya pengaruh negatif yang signifikan antara Green Perceived Risk terhadap Green Trust atau dapat dikatakan bahwa $\mathrm{H} 2$ diterima.

Persamaan 2:

\begin{tabular}{|cccc|}
\hline $\mathrm{GPI}=0.42^{*} \mathrm{GT}+0.37^{*} \mathrm{GPV}-0.11^{*} \mathrm{GPR}$, Errorvar. $=0.41, \mathrm{R}^{2}=0.59$ \\
$(0.093)$ & $(0.085)$ & $(0.071)$ & $(0.10)$ \\
4.52 & 4.40 & -1.60 & 4.78 \\
\hline
\end{tabular}

Sedangkan pada persamaan struktural 2 dapat dilihat bahwa Green Trust (GT), Green Perceived Value (GPV), Green Perceived Risk (GPR) mempengaruhi Green Purchase Intention (GPI) sebesar 59\% dan sisanya sebesar $41 \%$ dijelaskan oleh variable lain yang tidak diteliti.

Melalui persamaan struktural ini dapat diketahui bahwa tidak terdapat pengaruh signifikan antara Green Perceived Risk terhadap Green Purchase Intention dengan nilai t-hitung sebesar -1.60 (t-value $>1,96$ ). Maka dari hasil persamaan ini pengaruh tersebut tidak signifkan pada Green Perceived Risk terhadap Green Purchase Intention.

Melalui persamaan struktural ini dapat diketahui bahwa terdapat pengaruh antara Green Perceived Value terhadap Green Purchase Intention dengan t-hitung sebesar 4.40 (t-value > 1,96). Maka dari hasil persamaan ini ada pengaruh positif langsung yang signifkan antara Green Perceived Value terhadap Green Purchase Intention. 
Melalui persamaan struktural ini dapat diketahui bahwa terdapat pengaruh yang signifikan antara Green Trust terhadap Green Purchase Intention dengan nilai t-hitung sebesar 4.52 (t-value $>1,96$ ). Maka dari hasil persamaan ini dapat digunakan untuk mejawab rumusan masalah ketiga, yaitu ada pengaruh negatif langsung yang signifkan antara Green Trust terhadap Green Purchase Intention atau dapat dikatakan bahwa $\mathrm{H} 3$ diterima.

Tabel 4

Hubungan Direct - Indirect Effect

\begin{tabular}{|c|c|c|c|c|c|}
\hline \multicolumn{3}{|c|}{ Direct Effect } & \multicolumn{3}{|c|}{ Indirect Effect } \\
\hline Hubungan & $\begin{array}{c}\text { Std. } \\
\text { Estimate }\end{array}$ & $T$-value & Hubungan & $\begin{array}{c}\text { Std. } \\
\text { Estimate }\end{array}$ & $T$-value \\
\hline$G P V \rightarrow G P I$ & 0.37 & 4.40 & $\begin{array}{l}\text { GPV } \rightarrow \text { GT } \\
\rightarrow \text { GPI }\end{array}$ & 0.20 & 3.80 \\
\hline$G P R \rightarrow G P I$ & -0.11 & -1.60 & $\begin{array}{l}G P R \rightarrow G T \\
\rightarrow G P I\end{array}$ & -0.13 & -3.09 \\
\hline
\end{tabular}

Sumber: data yang diolah (2017)

Berdasarkan hasil dalam penelitian ini dapat diketahui pengaruh langsung (direct effect) antara green perceived value terhadap green purchase intention. Lain halnya pada green perceived risk terhadap green purchase intention tidak terdapat pengaruh langsung. Berdasarkan hasil penelitian ini dapat diketahui bahwa terdapat pengaruh tidak langsung (indirect effect) antara green Perceived Value dan Green Perceived Risk terhadap Green Purchase Intention dengan Green Trust sebagai mediasi.

Dalam penelitian ini green perceived value memiliki pengaruh langsung secara signifikan terhadap green purchase intention (GPI) sehingga hipotesis ini diterima, hal ini mendukung hasil yang serupa dengan penelitian terdahulu oleh Chen \& Chang (2012) dimana green perceived value (GPV) merupakan salah satu faktor yang berpengaruh positif terhadap green purchase intention (GPI). Green perceived risk (GPR) tidak memiliki pengaruh negatif yang signifikan terhadap green purchase intention (GPI), hal ini menunjukkan hasil yang tidak sesuai dengan penelitian Chen \& Chang (2012) dan Chen \& Ching-Hsun (2011) .

Green Trust dapat dipengaruhi oleh kedua variabel green perceived value, dan green perceived risk dimana konsumen akan meningkatkan kepercayaannya terhadap green product karena konsumen dapat merasakan nilai-nilai green yang terkandung didalam green product dan kecilnya risiko dari green product tersebut akan meningkatkan kepercayaan konsumen pada produk ramah lingkungan. 
Green purchase intention (GPI) dapat dipengaruhi oleh variabel green trust (GT) dan dapat disimpulkan bahwa kepercayaan konsumen mempengaruhi niat beli akan green product.

Green trust (GT) memediasi secara signifikan green perceived value (GPV) terhadap green purchase intention (GPI). Hasil penelitian ini sama dengan hasil penelitian Chen \& Chang (2012) yaitu meningkatnya green perceived value dapat meningkatkan green trust dan selanjutnya green purchase intention. Green trust (GT) tidak memediasi pengaruh secara signifikan green perceived risk (GPR) terhadap green purchase intention (GPI). Hasil penelitian ini berbeda dengan hasil penelitian Chen \& Chang (2012) yaitu green perceived risk memiliki pengaruh negatif terhadap green trust dan green purchase intention, dimana dengan menurunnya green perceived risk dapat meningkatkan green trust dan selanjutnya green purchase intention.

Green perceived value memiliki pengaruh langsung secara signifikan terhadap green purchase intention (GPI) sehingga hipotesis ini diterima, hal ini mendukung hasil yang serupa dengan penelitian terdahulu oleh Chen \& Chang (2012) dimana green perceived value (GPV) merupakan salah satu faktor yang berpengaruh positif terhadap green purchase intention (GPI). Green perceived risk (GPR) tidak memiliki pengaruh negatif yang tidak signifikan terhadap green purchase intention (GPI), hal ini menunjukkan hasil yang tidak sesuai dengan penelitian Chen \& Chang (2012). Adanya perbedaan dalam hasil penelitian ini menunjukkan bahwa konsumen tidak merasakan bahwa resiko dari green product tersebut dapat mengubah minat beli mereka.

Dengan hasil yang ditunjukan dapat ditarik kesimpulan bahwa kepercayaan memiliki pengaruh yang cukup kuat pada penelitian ini. Dimana untuk membuat konsumen berniat untuk membeli produk ini dibutuhkan kepercayaan akan kinerja produk tersebut.

\section{KESIMPULAN DAN SARAN}

Green Perceived Value berpengaruh signifikan terhadap Green Purchase Intention. Green Perceived Value berpengaruh signifikan terhadap Green Purchase Intention melalui Green Trust sebagai mediasi pada calon konsumen Air Conditioner Inverter Series LG Electronics. Green Perceived Risk tidak berpengaruh signifikan terhadap Green Purchase Intention. Green Perceived Risk berpengaruh signifikan terhadap Green Purchase Intention melalui Green Trust sebagai mediasi pada calon konsumen Air Conditioner

Penelitian ini mengkonfirmasi pentingnya Green Trust dalam menciptakan niat pembelian konsumen. Hal ini bisa menjadi pertimbangan bagi LG Electronics 
untuk lebih giat menanamkan kepercayaan masyarakat tentang green product yang dijualnya. Misalnya, perusahaan tersebut dapat merekrut sales dan penjaga konter yang mempunyai kompetensi untuk memberikan informasi tentang produk hijau.

Penulis memberi saran untuk memperluas penelitian terhadap variabelvariabel hijau lainnya seperti green brand image dan green satisfaction dengan tujuan untuk memperkaya penelitian-penelitian empiris yang ada.

\section{DAFTAR PUSTAKA}

Aaker, D. (1996). Building Strong Brands. New York: NY.

Albino, V., Balice, A., \& Dangelico, R. (2009). Environmental strategies and green product development: An overview on sustainbility-driven companies. Business Strategy and the Environment, 18 (2), 83-96.

Al-Salaymeh, .. M. (2013). The Application of the Concept of Green Marketing in the Productive Companies form the Perspective of Workers. Interdisciplinary journal of contemporoary VOL 4, NO 12, 634-641.

Baumann, F., Boons, F., \& Bragd, A. (2002). Mapping the green product development field: engineering, policy and business perspectif. Journal of Cleaner Production, 409-425.

Bolton, R., \& Drew, J. (1991). A multistage model of consumers' assessment of service quality and value. Journal of Consumer Reasearch, Vol. 17 No. 4, 375-84.

Cherian, J. a. (2017). Green Marketing: A Study of Consumers' Attitude towards Environment Friendly Products. Journal of Asian Social Science, Vol. 8, No. 12, pp. 117-126.

Gopalakrishnan, M. S. (2013). A Micro analysis on Dissect of Consumer's to Procure Green Product. Life Science Journal, 10 (2).

Jain, S., \& Kaur, G. (2004). Green Marketing: an Indian perspective. Decision, Vol 31 No.2, 168-209.

Kotler, P. \&. (2012). Marketing Management (14th ed). Upper Saddle River, New Jersey: Pearson Prentice Hall.

Kwok, M. L. (2015). Examining How Enviromental Concern Affects Purchase Intention: Mediating Role Of Perceived Trust And Moderating Role Of Perceived Risk. Contemporary Management Research. 11(2), 143-152. 
Mitchell, V. (1999). Consumer Perceived risk: conceptualization and models. European Journal of Marketing, 163-95.

Patterson, P. \&. (1997). Modeling the relationship beetwin perceived value, satisfaction, and re-purchase intentions in a business to business, service context: an empirical examination. International Journal of service industry management, 101-34.

Peattie, K. (1995). Enviromental Marketing Management, Pitman Publishing, London.

Peter, J., \& Ryan, M. (1976). An investigation of perceived risk at the brand level. Journal of Marketing Research Vol. 13 No. 2, pp. 184-9.

Polonsky, M. (1994). Green Marketing regulation in the US and Australia: the Australian checklis. Greenes Managemant International, Vol.5, 44-53.

Sarkar, A. N. (2012). Green branding and eco-innovations for evolving a sustainable green marketing strategy. Asia-Pacific . Journal of Management Research and Innovation, Vol 8, 39-58.

Schiffman, L., \& Kanuk, L. (2011). Consumer Behavior. Upper Saddle River, New Jersey: Prentice Hall.

Shamsadani, P. G. (1993). Exploring Green Consumers In An Oriental Culture: Role of Personal and Marketing Mix Factors. Advances in Consumer Research. , $20: 491$.

Steenkamp, J., \& Geyskens, I. (2006). How country characteristics affect the perceived value of the web sites. Journal of Marketing, Vol. 70 No. 3, 13650 .

Sweeney, J. S. (1999). The role of perceived risk in the quality-value relationship: a study in retail environtment. Journal of Retailing, Vol. 75 No. 1, 77-105.

Wood, C., Scheer, L., Corfman, K., \& Lynch, J. (1996). "Incorporating perceived risk into models of consumer deal". Advances in consumers research vol.23 Aassociation for Consumer Research, Provo, UT, pp. 399-340.

Yazdanifard, R. \&. (t.thn.). The impact of green marketing on customer satisfaction and environmental safety. 2011. 